\title{
Automated determination of internal points of the coordinate grid of the blasted rock mass
}

\author{
Bayan Rakishev ${ }^{1, *}$, Zaure Rakisheva ${ }^{2}$, Alma Auezova $^{3}$, and Asfandiyar Orynbay ${ }^{1}$ \\ ${ }^{1}$ K.I. Satpayev Kazakh National Research Technical University (Satbayev Unuversity), A15P4X4, \\ Almaty, Satbayev Str., 22, Republic of Kazakhstan \\ ${ }^{2}$ Al-Farabi Kazakh National University, 050040, Almaty, al-Farabi Ave., 71/23, Republic of \\ Kazakhstan \\ ${ }^{3}$ Almaty University of Power Engineering and Telecommunications, 050013, Almaty, Baytursynova \\ Str., 126/1, Republic of Kazakhstan
}

\begin{abstract}
An automated method for determining the internal points of the coordinate grid of the blasted rock mass is described. It is based on the method of determining the nodal points of the coordinate grid of the blasted rock mass, which is based on taking into account the dependencies that connect the initial parameters of the blasting rock mass with the final location of the fixed points of the blasted rock mass. The determining factors are the specific height and width of the collapse, the coefficient of loosening of the rocks. The method of analysis of experimental and industrial mass explosions in quarries, methods of analytical geometry, matrix theory and linear algebra are used. For the first time in mining, an analytical method has been developed for determining the internal points of the coordinate grid of an exploded block. It includes the established functions of the movement of nodal points, components of the vectors of movement of nodal and internal points of the coordinate grid. The established dependencies allow one to determine the displacements of any point inside the coordinate grid of the blasted block from the initial coordinates of the nodal and internal points.
\end{abstract}

\section{Introduction}

Predicting the placement of dissimilar rocks of a ledge in the collapse of blasted rocks is extremely important in mining. It is relevant when mining complex structural rock ores, when shipping rocks of various lumpiness from different zones of collapse. Establishing the internal structure of blasted rocks will make it possible to reasonably choose rational technologies for drilling, blasting, excavating and loading operations and increase the efficiency of open development of multicomponent, complex structural deposits.

The formation of the collapse of the blasted rocks obeys the laws arising from the model of the phased destruction of the rock mass by the explosion of explosive charges (EX) $[1,2]$. According to this model, the main destruction of rocks occurs in the first stage of an explosion under the influence of stress waves excited in the medium by an explosive charge explosion, and the gaseous products of the explosion themselves. In the second stage of the

*Corresponding author: b.rakishev@mail.ru 
explosion, all the rock mass ejected by the explosion products in space occupies a position determined by the specific value of the initial speed of the beaten part of the ledge. It depends on the physicomechanical properties of the rocks of the blasting block, the physicochemical characteristics of the explosive used and the location parameters of the explosive charges in the explosive mass. In the third stage, the ejected rocks are sagged of the crushed part of the ledge in the field of gravity and a collapse of the blasted rock mass is formed. The fixed elements of the blasting block in the collapse occupy the positions determined by the initial data of a specific mass explosion. Such an approach to the mechanism of rock destruction by an explosion is used in the works of scientists from near [4-8] and far abroad [9-13].

In studies [4-13], the general configuration of rock collapse and the yield of oversized pieces are usually determined. The issue of the internal structure of the collapse is not given sufficient attention. In [14], old experimental data on the placement of various layers of a ledge block in a camber are presented. However, new data on the detailing of the internal structure of the collapse in modern mountain literature does not occur. Therefore, an indepth study of the process of formation of the collapse of blasted rock mass in quarries using the numerical method and computer technology in terms of establishing its internal structure is a very urgent task.

The formation of rock collapse was considered in detail in [2, 3]. A graph-analytical method has been developed for determining the elements of an explosive block after an explosion. Developing these ideas, we consider below analytical methods for determining the nodal and internal points of the coordinate grid of an exploded block and their software support.

Goal. Development of an analytical method for determining the position of fixed internal points of the coordinate grid of the blasted rock mass and software for its implementation.

Practical significance. A computer program has been created for the automated determination of the internal points of the coordinate grid of the blasted rock mass, taking into account the determining factors. Using the program, the positions of any points of the blasted block can be found quickly and accurately enough for various parameters and conditions of blasting rock masses. The positions of the internal points of the coordinate grid of the blasted block thus established serve as a tool for determining the structural characteristics of the collapse of blasted rocks.

\section{Geometric characteristics of the elements of the blasting block of ledge}

To create coordinate grids, the blasting block should be divided into a certain number of parts by virtual planes parallel to the ledge slope and the horizon. For example, with a single-row arrangement of wells, the blasting block with the indicated planes can be divided into 16 equal parts (elements) (Fig. 1a). With a two-row arrangement of wells, the blasted block is divided into 24 parts (elements), i.e. to the case under consideration are added two inclined equal-sized layers with a thickness equal to half the distance between the rows of wells, etc. (Fig. 2a).

Traces of horizontal dividing planes in the section of the ledge are horizontal contouring lines of the elements of the ledge. They also include traces of the roof and the soles of the ledge. Similarly, traces of inclined breaking planes are inclined contour lines of the ledge elements under consideration. They include the slope of the ledge and the line of separation of the detonated block from the rock mass (Fig. 1a, 2a).

Previous studies [2,3] revealed patterns of placement of fixed elements of the blasting block in the collapse and established the position of the contouring lines for various 
methods of blasting. From their analysis it follows that the placement of the ledge elements in the collapse is completely determined by the position of their contouring lines in the blasted rock mass.
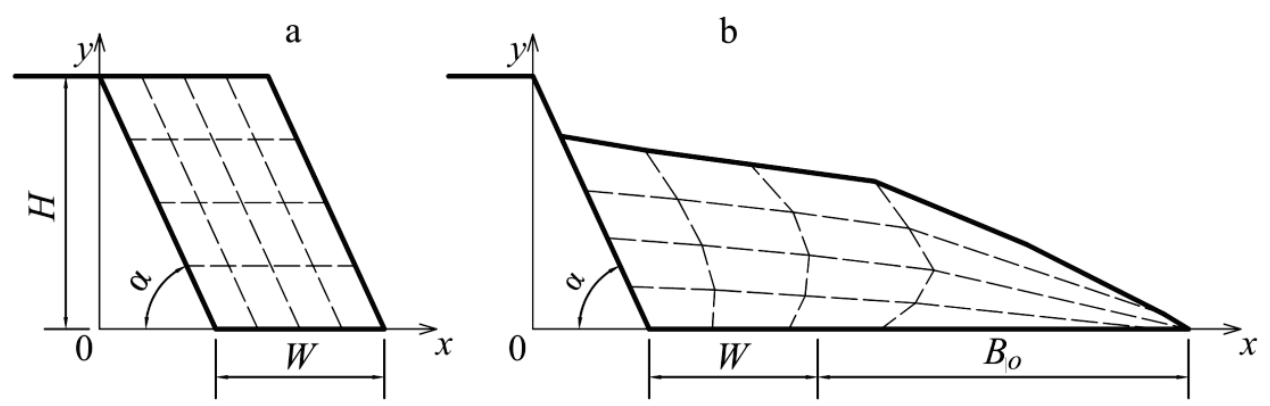

Fig. 1. Layout of the ledge elements in the blasting (a) and blasted blocks (b) with single-row blasting.
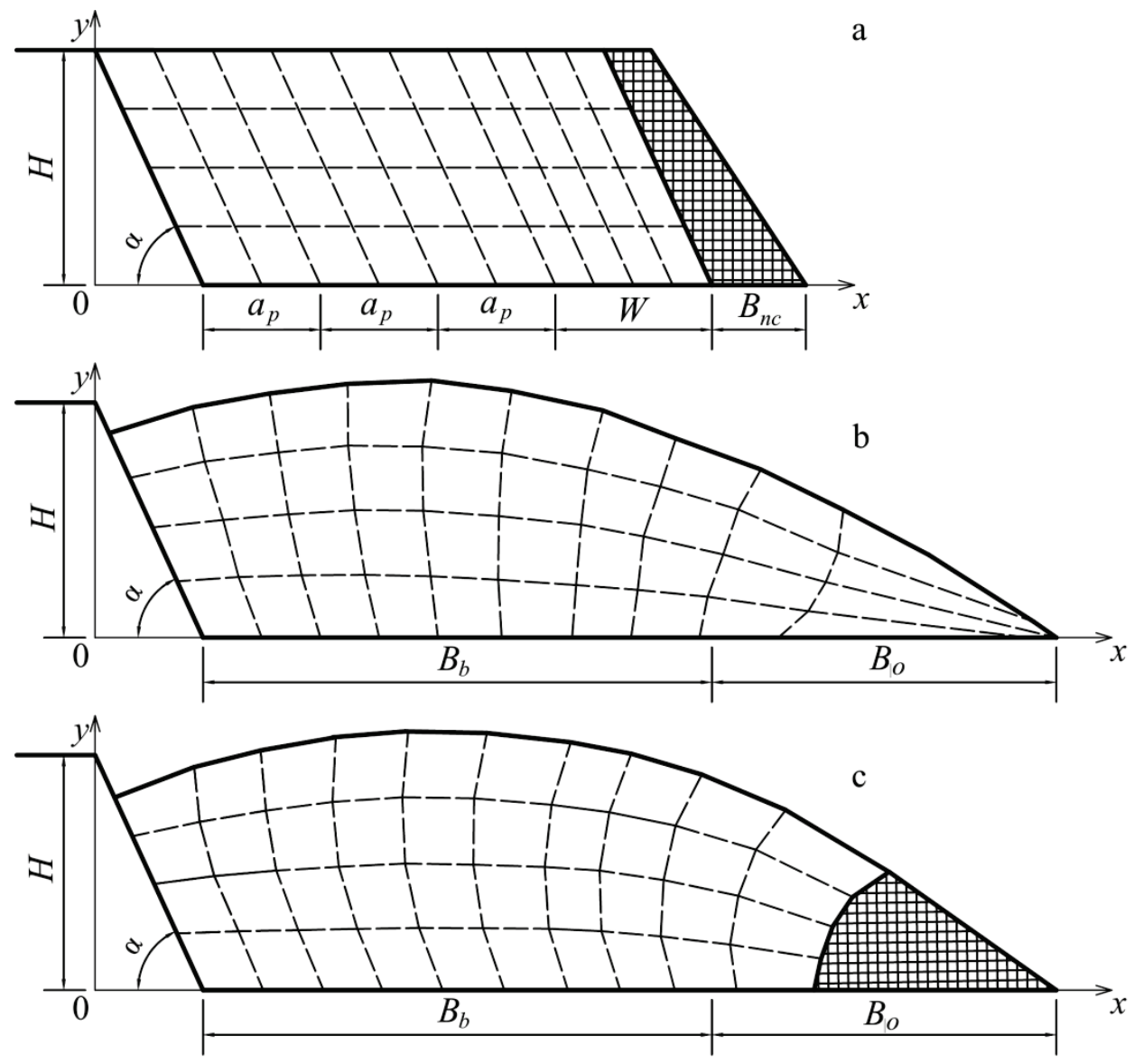

Fig. 2. Layout of the ledge elements in the blasting (a) and blasted blocks with a four-row short blast on a free surface (b) and with a retaining wall (c).

Moreover, the set of mutually intersecting horizontal and inclined contouring lines of the elements of the blasting block in the section is called the coordinate grid of the blasting block (Fig. 1a, 2a). The set of mutually intersecting deformed horizontal and inclined 
contouring lines of the ledge elements in the collapse is called the coordinate grid of the blasted block (Fig. 1b, 2b, 2c).

When determining the coordinate grid of the blasted block of the rock mass, it is assumed that the block elements from the initial (before the explosion) and to the final (after the explosion) position pass, bypassing all the intermediate positions of the elements under consideration in the process of moving fragmented rocks in the gravity field. The influence of these forces and the formation of rock breakup is taken into account by the specific position of the individual elements of the blasted block in the blasted rock mass.

The geometrical characteristics of the elements of the blasted block include their areas, contouring lines, the loosening coefficients of the elements along horizontal and inclined layers, and the coordinates of the nodal points of the coordinate grid of the blasted block. They are presented in fig. $1 \mathrm{~b}, 2 \mathrm{~b}, 2 \mathrm{c}$. The nodal points of the coordinate grid of the blasted block are the intersection points of the horizontal and inclined contouring lines of the elements of the blasted block. The numbering of layers vertically $\gamma(\gamma=1,2 \ldots 4)$ is from bottom to top, and horizontally $\delta(\delta=1,2 \ldots 10)$ from left to right. This order corresponds to the indices of the considered characteristics of the elements of the blasted block $\left(S_{1,1}^{*}, S_{1,2}^{*}, \ldots, S_{4,10}^{*} ; k_{p 1,1}, k_{p 1,2}, \ldots, k_{p 4,10}\right)$.

\section{Analytical determination of the position of the node points of the coordinate net of the blasted block}

The coordinates of the nodal points of the grid of the blasted block are determined by the following formulas (see fig. 1 and 2):

$$
x_{i, j}=k_{i, j}^{x}\left(\varepsilon_{\lambda}+m_{j}\right) ; \quad y_{i, j}=k_{i, j}^{y} \cdot l_{i},
$$

where $x_{i, j}, y_{i, j}$ - the coordinates of the nodal points of the grid, i.e. intersection points $i$-th and $j$-th contouring lines of the elements of the blown block ledge, $i(i=1,2 \ldots 5)$, $j(j=1,2 \ldots 11) ; k_{i, j}^{x}, k_{i, j}^{y}$ - the proportionality coefficients of the change in the coordinates of the nodal points, respectively, in the horizontal and vertical directions; $\varepsilon_{\lambda}, m_{j}, l_{i}$ - equation constants.

The constant $\varepsilon_{\lambda}$ is the same for single-row and multi-row arrangement of wells and is determined by the dependence:

$$
\varepsilon_{\lambda}=\left(h-l_{i}\right) \cdot \operatorname{ctg} \alpha
$$

Here, the indices $\varepsilon_{\lambda}$ denote the numbers of nodal points on the line of separation of rocks from the massif from the bottom up $(\lambda=1,2 \ldots 5), h$ is the height of the ledge, $\alpha$ is the slope angle of the ledge, $l_{i}$ is the ordinate of the $i$-th contouring horizontal line of the blasting block.

$$
l_{1}=0 ; \quad l_{2}=\frac{h}{4} ; l_{3}=\frac{h}{2} ; l_{4}=\frac{3 h}{4} ; l_{5}=h .
$$

The constant $m_{j}$ is the distance (horizontal) between the contour line under consideration and the line of separation of rocks from the massif in the blasting unit.

Single row blasting: 


$$
m_{1}=0 ; \quad m_{2}=\frac{W}{4} ; \quad m_{3}=\frac{W}{2} ; m_{4}=\frac{3 W}{4} ; m_{5}=W
$$

Four-row short blast:

$$
\begin{gathered}
m_{1}=0 ; \quad m_{2}=\frac{a_{p}}{2} ; \quad m_{3}=a_{p} ; m_{4}=\frac{3 a_{p}}{2} ; m_{5}=2 a_{p} ; m_{6}=\frac{5 a_{p}}{2} ; m_{7}=3 a_{p} ; \\
m_{8}=3 a_{p}+\frac{W}{4} ; \quad m_{9}=3 a_{p}+\frac{W}{2} ; m_{10}=3 a_{p}+\frac{3 W}{4} ; m_{11}=3 a_{p}+W .
\end{gathered}
$$

The proportionality coefficients of the change in the coordinates of the nodal points are related to the integral characteristic of the camber state - with the coefficient of loosening of rocks in the corresponding camber layers $\left(k_{p(\gamma, \delta)}\right)$ and with a ratio taking into account the length of the discarded part of the camber $B_{o}$, the constants $l_{i}, m_{j}$ i.e. with parameters:

$$
p_{\gamma, \delta}^{x}=k_{p(\gamma, \delta)} \sqrt{\frac{B_{o}}{m_{j}}}, p_{\gamma, \delta}^{y}=k_{p(\gamma, \delta)} \sqrt{\frac{B_{o}}{l_{i}}},
$$

where $\gamma=1,2,3,4, \delta=1,2 \ldots 10, i=\gamma+1, j=\delta+1$.

Approximating polynomial equations for determining the required proportionality coefficients of the points of the coordinate grid of rock collapse are as follows [14]:

$$
\begin{aligned}
& k_{i, j}^{x}=a_{i}^{x} p_{\gamma, \delta}^{x{ }^{5}}+b_{i}^{x} p_{\gamma, \delta}^{x}{ }^{4}+c_{i}^{x} p_{\gamma, \delta}^{x{ }^{3}}+d_{i}^{x} p_{\gamma, \delta}^{x}{ }^{2}+e_{i}^{x} p_{\gamma, \delta}^{x}+f_{i}^{x}, \\
& k_{i, j}^{y}=a_{j}^{y} p_{\gamma, \delta}^{y}{ }^{2}+b_{j}^{y} p_{\gamma, \delta}^{y}+c_{j}^{y},
\end{aligned}
$$

where $a_{i}^{x}, b_{i}^{x}, c_{i}^{x}, d_{i}^{x}, e_{i}^{x}, f_{i}^{x}$ - the constants of the first equation (7) associated with the $i$-th horizontal contour line; $a_{j}^{y}, b_{j}^{y}, c_{j}^{y}$ - constants of the second equation (8) associated with the $j$-th inclined contouring line. The found numerical values of the proportionality coefficients of the coordinates of the nodal points are given in table 1-2.

Table. 1. Coefficients of proportionality of nodal points in single row blasting.

\begin{tabular}{|c|c|c|c|c|}
\hline $\mathrm{k}_{1,1}^{\mathrm{x}}, \mathrm{k}_{1,1}^{\mathrm{y}}$ & $\mathrm{k}_{1,2}^{\mathrm{x}}, \mathrm{k}_{1,2}^{\mathrm{y}}$ & $\mathrm{k}_{1,3}^{\mathrm{x}}, \mathrm{k}_{1,3}^{\mathrm{y}}$ & $\mathrm{k}_{1,4}^{\mathrm{x}}, \mathrm{k}_{1,4}^{\mathrm{y}}$ & $\mathrm{k}_{1,5}^{\mathrm{x}}, \mathrm{k}_{1,5}^{\mathrm{y}}$ \\
\hline $1.00 ; 0$ & $1.13 ; 0$ & $1.28 ; 0$ & $1.43 ; 0$ & $1.74 ; 0$ \\
\hline $\mathrm{k}_{2,1}^{\mathrm{x}}, \mathrm{k}_{2,1}^{\mathrm{y}}$ & $\mathrm{k}_{2,2}^{\mathrm{x}}, \mathrm{k}_{2,2}^{\mathrm{y}}$ & $\mathrm{k}_{2,3}^{\mathrm{x}}, \mathrm{k}_{2,3}^{\mathrm{y}}$ & $\mathrm{k}_{2,4}^{\mathrm{x}}, \mathrm{k}_{2,4}^{\mathrm{y}}$ & $\mathrm{k}_{2,5}^{\mathrm{x}}, \mathrm{k}_{2,5}^{\mathrm{y}}$ \\
\hline $1.11 ; 0.67$ & $1.41 ; 0.62$ & $1.59 ; 0.53$ & $1.79 ; 0.41$ & $2.45 ; 0$ \\
\hline $\mathrm{k}_{3,1}^{\mathrm{x}}, \mathrm{k}_{3,1}^{\mathrm{y}}$ & $\mathrm{k}_{3,2}^{\mathrm{x}}, \mathrm{k}_{3,2}^{\mathrm{y}}$ & $\mathrm{k}_{3,3}^{\mathrm{x}}, \mathrm{k}_{3,3}^{\mathrm{y}}$ & $\mathrm{k}_{3,4}^{\mathrm{x}}, \mathrm{k}_{3,4}^{\mathrm{y}}$ & $\mathrm{k}_{3,5}^{\mathrm{x}}, \mathrm{k}_{3,5}^{\mathrm{y}}$ \\
\hline $1.28 ; 0.72$ & $1.69 ; 0.66$ & $1.94 ; 0.58$ & $2.17 ; 0.47$ & $2.89 ; 0$ \\
\hline $\mathrm{k}_{4,1}^{\mathrm{x}}, \mathrm{k}_{4,1}^{\mathrm{y}}$ & $\mathrm{k}_{4,2}^{\mathrm{x}}, \mathrm{k}_{4,2}^{\mathrm{y}}$ & $\mathrm{k}_{4,3}^{\mathrm{x}}, \mathrm{k}_{4,3}^{\mathrm{y}}$ & $\mathrm{k}_{4,4}^{\mathrm{x}}, \mathrm{k}_{4,4}^{\mathrm{y}}$ & $\mathrm{k}_{4,5}^{\mathrm{x}}, \mathrm{k}_{4,5}^{\mathrm{y}}$ \\
\hline $1.81 ; 0.73$ & $2.03 ; 0.68$ & $2.30 ; 0.62$ & $2.42 ; 0.53$ & $3.20 ; 0.08$ \\
\hline $\mathrm{k}_{5,1}^{\mathrm{x}}, \mathrm{k}_{5,1}^{\mathrm{y}}$ & $\mathrm{k}_{5,2}^{\mathrm{x}}, \mathrm{k}_{5,2}^{\mathrm{y}}$ & $\mathrm{k}_{5,3}^{\mathrm{x}}, \mathrm{k}_{5,3}^{\mathrm{y}}$ & $\mathrm{k}_{5,4}^{\mathrm{x}}, \mathrm{k}_{5,4}^{\mathrm{y}}$ & $\mathrm{k}_{5,5}^{\mathrm{x}}, \mathrm{k}_{5,5}^{\mathrm{y}}$ \\
\hline$-; 0.76$ & $2.66 ; 0.71$ & $2.58 ; 0.65$ & $2.70 ; 0.58$ & $2.93 ; 0.33$ \\
\hline
\end{tabular}

Rational blasting parameters for diorite-porphyrite rocks: $\rho_{0}=2830 \mathrm{~kg} / \mathrm{m}^{3}$, $c=5100 \mathrm{~m} / \mathrm{s}, \sigma_{\text {com }}=190 \mathrm{MPa}, \sigma_{\text {ten }}=16 \mathrm{MPa}, \mathrm{v}=0.24$. Parameters of the arrangement of 
charges: the height of the step $h=15.0 \mathrm{~m}$ the resistance line along the sole of the step $W=10.0 \mathrm{~m}$ the distance between the wells $a=7.5 \mathrm{~m}$, between the rows of wells $a_{p}=7.5 \mathrm{~m}$, the length of the crossbar $l_{n}=2.0 \mathrm{~m}$, stemming length $l_{3}=7.0 \mathrm{~m}$, borehole charge mass $Q=450 \mathrm{~kg}$. The location of the wells is single-row, four-row. Short-delayed blasting (SDB) on a free plane and with a retaining wall. The width of the discarded part of the camber is $22.0 \mathrm{~m}$. The width of the retaining wall at the top $B_{n c}=3.0 \mathrm{~m}$, at the bottom $B_{n c}=6.0 \mathrm{~m}$. The width of the retaining wall at the bottom is part of the width of the discarded part of the camber. The specific consumption of explosives with single-row blasting $q=0.4 \mathrm{~kg} / \mathrm{m}^{3}$, four-row blasting $q=0.49 \mathrm{~kg} / \mathrm{m}^{3}$.

Table. 2. Coefficients of proportionality of nodal points in the case of four-row short-delayed blasting on a free surface.

\begin{tabular}{|c|c|c|c|c|c|c|c|c|c|c|}
\hline $\begin{array}{l}\mathrm{k}_{1,1}^{\mathrm{x}}, \\
\mathrm{k}^{\mathrm{y}}{ }_{1,1}\end{array}$ & $\begin{array}{l}\mathrm{k}^{\mathrm{x}}{ }_{1,2}, \\
\mathrm{k}^{\mathrm{y}}{ }_{1,2}\end{array}$ & $\begin{array}{l}\mathbf{k}_{1,3}^{\mathrm{x}}, \\
\mathrm{k}^{\mathrm{y}}{ }_{1,3}\end{array}$ & $\begin{array}{l}\mathrm{k}^{\mathrm{x}}{ }_{1,4}, \\
\mathrm{k}^{\mathrm{y}}{ }_{1,4}\end{array}$ & $\begin{array}{l}\mathrm{k}_{1,5}^{\mathrm{x}}, \\
\mathrm{k}^{\mathrm{y}}{ }_{1,5}\end{array}$ & $\begin{array}{l}\mathrm{k}_{1,6}^{\mathrm{x}}, \\
\mathrm{k}^{\mathrm{y}}{ }_{1,6}\end{array}$ & $\begin{array}{l}\mathrm{k}^{\mathrm{x}}{ }_{1,7}, \\
\mathrm{k}^{\mathrm{y}}{ }_{1,7}\end{array}$ & $\begin{array}{l}\mathrm{k}_{1,8}^{\mathrm{x}}, \\
\mathrm{k}^{\mathrm{y}}{ }_{1,8}\end{array}$ & $\begin{array}{l}\mathrm{k}_{1,9}^{\mathrm{x}}, \\
\mathrm{k}^{\mathrm{y}}{ }_{1,9}\end{array}$ & $\begin{array}{c}\mathrm{k}_{1,10}^{\mathrm{x}}, \\
\mathrm{k}^{\mathrm{y}}{ }_{1,10}\end{array}$ & $\begin{array}{l}\mathrm{k}_{1,11}^{\mathrm{x}}, \\
\mathrm{k}_{1,11}^{\mathrm{y}}\end{array}$ \\
\hline $\begin{array}{l}1.00 \\
0.00\end{array}$ & $\begin{array}{l}1.00 \\
0.00\end{array}$ & $\begin{array}{l}1.00 \\
0.00\end{array}$ & $\begin{array}{l}1.00 \\
0.00\end{array}$ & $\begin{array}{l}1.00 \\
0.00\end{array}$ & $\begin{array}{l}1.01 \\
0.00\end{array}$ & $\begin{array}{l}1.04 ; \\
0.00\end{array}$ & $\begin{array}{l}1.07 \\
0.00\end{array}$ & $\begin{array}{l}1.12 ; \\
0.00\end{array}$ & $\begin{array}{l}1.18 \\
0.00\end{array}$ & $\begin{array}{l}1.32 \\
0.00\end{array}$ \\
\hline $\begin{array}{l}\mathrm{k}_{2,1}^{\mathrm{x}}, \\
\mathrm{k}^{\mathrm{y}}{ }_{2,1}\end{array}$ & $\begin{array}{l}\mathrm{k}^{\mathrm{x}}{ }_{2,2}, \\
\mathrm{k}^{\mathrm{y}}{ }_{2,2}\end{array}$ & $\begin{array}{l}\mathrm{k}_{2,3}^{\mathrm{x}}, \\
\mathrm{k}^{\mathrm{y}}{ }_{2,3}\end{array}$ & $\begin{array}{l}\mathrm{k}_{2,4}^{\mathrm{x}}, \\
\mathrm{k}^{\mathrm{y}}{ }_{2,4}\end{array}$ & $\begin{array}{l}\mathrm{k}_{2,5}^{\mathrm{x}}, \\
\mathrm{k}^{\mathrm{y}}{ }_{2,5}\end{array}$ & $\begin{array}{l}\mathrm{k}_{2,6}^{\mathrm{x}}, \\
\mathrm{k}^{\mathrm{y}}{ }_{2,6}\end{array}$ & $\begin{array}{l}\mathrm{k}_{2,7}^{\mathrm{x}}, \\
\mathrm{k}_{2,7}^{\mathrm{y}}\end{array}$ & $\begin{array}{l}\mathrm{k}_{2,8}^{\mathrm{x}}, \\
\mathrm{k}^{\mathrm{y}}{ }_{2,8}\end{array}$ & $\begin{array}{l}\mathrm{k}_{2,9}^{\mathrm{x}}, \\
\mathrm{k}^{\mathrm{y}}{ }_{2,9}\end{array}$ & $\begin{array}{l}\mathrm{k}_{2,10}^{\mathrm{x}} \\
\mathrm{k}^{\mathrm{y}}{ }_{2,10}\end{array}$ & $\begin{array}{l}\mathrm{k}_{2,11}^{\mathrm{x}}, \\
\mathrm{k}^{\mathrm{y}}{ }_{2,11}\end{array}$ \\
\hline $\begin{array}{l}1.01 ; \\
0.96\end{array}$ & $\begin{array}{l}1.03 ; \\
1.03\end{array}$ & $\begin{array}{l}1.04 ; \\
1.06\end{array}$ & $\begin{array}{l}1.05 ; \\
1.07\end{array}$ & $\begin{array}{l}1.06 ; \\
1.05\end{array}$ & $\begin{array}{l}1.08 ; \\
0.99\end{array}$ & $\begin{array}{l}1.11 ; \\
0.90\end{array}$ & $\begin{array}{l}1.15 ; \\
0.81\end{array}$ & $\begin{array}{l}1.20 ; \\
0.70\end{array}$ & $\begin{array}{l}1.30 \\
0.45\end{array}$ & $\begin{array}{l}1.58 \\
0.00\end{array}$ \\
\hline $\begin{array}{l}\mathrm{k}_{3,1}^{\mathrm{x}}, \\
\mathrm{k}_{3,1}^{\mathrm{y}}\end{array}$ & $\begin{array}{l}\mathrm{k}_{3,2}^{\mathrm{x}}, \\
\mathrm{k}_{3,2}^{\mathrm{y}}\end{array}$ & $\begin{array}{l}\mathrm{k}_{3,3}^{\mathrm{x}}, \\
\mathrm{k}_{3,3}^{\mathrm{y}}\end{array}$ & $\begin{array}{l}\mathrm{k}_{3,4}^{\mathrm{x}}, \\
\mathrm{k}^{\mathrm{y}}{ }_{3,4}\end{array}$ & $\begin{array}{l}\mathrm{k}_{3,5}^{\mathrm{x}}, \\
\mathrm{k}_{3,5}^{\mathrm{y}}\end{array}$ & $\begin{array}{l}\mathrm{k}_{3,6}^{\mathrm{x}}, \\
\mathrm{k}_{3,6}^{\mathrm{y}}\end{array}$ & $\begin{array}{l}\mathrm{k}_{3,7}^{\mathrm{x}}, \\
\mathrm{k}^{\mathrm{y}}{ }_{3,7}\end{array}$ & $\begin{array}{l}\mathrm{k}_{3,8}^{\mathrm{x}}, \\
\mathrm{k}_{3,8}^{\mathrm{y}}\end{array}$ & $\begin{array}{l}\mathrm{k}_{3,9}^{\mathrm{x}}, \\
\mathrm{k}_{3,9}^{\mathrm{y}}\end{array}$ & $\begin{array}{l}\mathrm{k}_{3,10}^{\mathrm{x}} \\
\mathrm{k}_{3,10}^{\mathrm{y}}\end{array}$ & $\begin{array}{l}\mathrm{k}_{3,11}^{\mathrm{x}}, \\
\mathrm{k}_{3,11}^{\mathrm{y}}\end{array}$ \\
\hline $\begin{array}{l}1.06 ; \\
0.94\end{array}$ & $\begin{array}{l}1.14 ; \\
1.00\end{array}$ & $\begin{array}{l}1.13 ; \\
1.05\end{array}$ & $\begin{array}{l}1.13 ; \\
1.09\end{array}$ & $\begin{array}{l}1.14 ; \\
1.08\end{array}$ & $\begin{array}{l}1.16 ; \\
1.03\end{array}$ & $\begin{array}{l}1.20 \\
0.96\end{array}$ & $\begin{array}{l}1.23 ; \\
0.86\end{array}$ & $\begin{array}{l}1.30 \\
0.71\end{array}$ & $\begin{array}{c}1.40 \\
0.47\end{array}$ & $\begin{array}{l}1.71 \\
0.00\end{array}$ \\
\hline $\begin{array}{l}\mathrm{k}_{4,1}^{\mathrm{x}}, \\
\mathrm{k}_{4,1}^{\mathrm{y}}\end{array}$ & $\begin{array}{l}\mathrm{k}_{4,2}^{\mathrm{x}}, \\
\mathrm{k}_{4,2}^{\mathrm{y}}\end{array}$ & $\begin{array}{l}\mathrm{k}_{4,3}^{\mathrm{x}}, \\
\mathrm{k}_{4,3}^{\mathrm{y}}\end{array}$ & $\begin{array}{l}\mathrm{k}_{4,4}^{\mathrm{x}}, \\
\mathrm{k}_{4,4}^{\mathrm{y}}\end{array}$ & $\begin{array}{l}\mathrm{k}_{4,5}^{\mathrm{x}}, \\
\mathrm{k}_{4,5}^{\mathrm{y}}\end{array}$ & $\begin{array}{l}\mathrm{k}_{4,6}^{\mathrm{x}}, \\
\mathrm{k}_{4,6}^{\mathrm{y}}\end{array}$ & $\begin{array}{l}\mathrm{k}_{4,7}^{\mathrm{x}}, \\
\mathrm{k}_{4,7}^{\mathrm{y}}\end{array}$ & $\begin{array}{l}\mathrm{k}_{4,8}^{\mathrm{x}}, \\
\mathrm{k}_{4,8}^{\mathrm{y}}\end{array}$ & $\begin{array}{l}\mathrm{k}_{4,9}^{\mathrm{x}} \\
\mathrm{k}_{4,9}^{\mathrm{y}}\end{array}$ & $\begin{array}{l}\mathrm{k}_{4,10}^{\mathrm{x}} \\
\mathrm{k}_{4,10}^{\mathrm{y}}\end{array}$ & $\begin{array}{l}\mathrm{K}_{4,11}^{\mathrm{x}}, \\
\mathrm{k}_{4,11}^{\mathrm{y}}\end{array}$ \\
\hline $\begin{array}{l}1.28 ; \\
0.91\end{array}$ & $\begin{array}{l}1.28 ; \\
1.00\end{array}$ & $\begin{array}{l}1.27 \\
1.05\end{array}$ & $\begin{array}{l}1.25 \\
1.09\end{array}$ & $\begin{array}{l}1.25 \\
1.08\end{array}$ & $\begin{array}{l}1.27 ; \\
1.05\end{array}$ & $\begin{array}{l}1.30 \\
0.95\end{array}$ & $\begin{array}{l}1.35 \\
0.86\end{array}$ & $\begin{array}{l}1.41 ; \\
0.73\end{array}$ & $\begin{array}{l}1.50 \\
0.48\end{array}$ & $\begin{array}{l}1.75 \\
0.09\end{array}$ \\
\hline $\begin{array}{l}\mathrm{k}_{5,1}^{\mathrm{x}}, \\
\mathrm{k}_{5,1}^{\mathrm{y}}\end{array}$ & $\begin{array}{l}\mathrm{k}_{5,2}^{\mathrm{x}}, \\
\mathrm{k}^{\mathrm{y}}{ }_{5,2}\end{array}$ & $\begin{array}{l}\mathrm{k}_{5,3}^{\mathrm{x}}, \\
\mathrm{k}_{5,3}^{\mathrm{y}}\end{array}$ & $\begin{array}{l}\mathrm{k}_{5,4}^{\mathrm{x}}, \\
\mathrm{k}^{\mathrm{y}}{ }_{5,4}\end{array}$ & $\begin{array}{l}\mathrm{k}_{5,5}^{\mathrm{x}}, \\
\mathrm{k}^{\mathrm{y}}{ }_{5,5}\end{array}$ & $\begin{array}{l}\mathrm{k}_{5,6}^{\mathrm{x}}, \\
\mathrm{k}_{5,6}^{\mathrm{y}}\end{array}$ & $\begin{array}{l}\mathrm{k}_{5,7}^{\mathrm{x}}, \\
\mathrm{k}^{\mathrm{y}}{ }_{5,7}\end{array}$ & $\begin{array}{l}\mathrm{k}_{5,8}^{\mathrm{x}}, \\
\mathrm{k}_{5,8}^{\mathrm{y}}\end{array}$ & $\begin{array}{l}\mathrm{k}_{5,9}^{\mathrm{x}}, \\
\mathrm{k}^{\mathrm{y}}{ }_{5,9}\end{array}$ & $\begin{array}{l}\mathrm{k}_{5,10}^{\mathrm{x}} \\
\mathrm{k}_{5,10}^{\mathrm{y}}\end{array}$ & $\begin{array}{l}\mathrm{k}_{5,11}^{\mathrm{x}}, \\
\mathrm{k}_{5,11}^{\mathrm{y}}\end{array}$ \\
\hline $\begin{array}{c}-; \\
0.87\end{array}$ & $\begin{array}{l}1.66 ; \\
0.98\end{array}$ & $\begin{array}{l}1.49 \\
1.04\end{array}$ & $\begin{array}{l}1.43 ; \\
1.08\end{array}$ & $\begin{array}{l}1.43 \\
1.09\end{array}$ & $\begin{array}{l}1.42 ; \\
1.05\end{array}$ & $\begin{array}{l}1.44 \\
0.94\end{array}$ & $\begin{array}{l}1.48 ; \\
0.85\end{array}$ & $\begin{array}{l}1.55 \\
0.72\end{array}$ & $\begin{array}{c}1.59 \\
0.54\end{array}$ & $\begin{array}{l}1.64 ; \\
0.35\end{array}$ \\
\hline
\end{tabular}

\section{Analytical determination of the internal points of the coordinate net of the blasted array block of breeds}

As a review of literature [15-19] shows, the solution to the problem under consideration can be invoked by the method of determining the displacements of points of finite elements, which is used in the mechanics of a continuous medium. It is called the finite element method $[17,18]$. Knowing the coordinates of the nodal points of the coordinate grid of the collapse of rocks, we can proceed to determine the displacement of the internal points of each element in the collapse. For this, it is necessary to use the element moving function [18]. In our case, a quadrangular element with nodes $\varphi, \chi, \psi, \omega$ (Fig. 3), the movement of each element of the node will have two components [18]:

$$
\left\{\boldsymbol{\delta}_{\varphi}\right\}=\left\{\begin{array}{l}
u_{\varphi} \\
v_{\varphi}
\end{array}\right\},
$$


where $u_{\varphi}, v_{\varphi}$ are the displacements of the nodal point of the coordinate grid of the blasted block in the horizontal and vertical directions, respectively.

The eight components of the movements of the coordinate grid element form a vector [18]:

$$
\{\boldsymbol{\delta}\}^{e}=\left\{\begin{array}{c}
\boldsymbol{\delta}_{\varphi} \\
\boldsymbol{\delta}_{\chi} \\
\boldsymbol{\delta}_{\psi} \\
\boldsymbol{\delta}_{\omega}
\end{array}\right\},
$$

These components are determined by the coordinates of the nodal points of the coordinate grid of the blasted block, i.e.:

$$
\begin{gathered}
u_{\varphi}=x_{i, j}, v_{\varphi}=y_{i, j}, u_{\chi}=x_{i+1, j}, v_{\chi}=y_{i+1, j}, \\
u_{\psi}=x_{i+1, j+1}, v_{\psi}=y_{i+1, j+1}, u_{\omega}=x_{i, j+1}, v_{\omega}=y_{i, j+1} .
\end{gathered}
$$

The movement of points within an element must be uniquely determined by these eight values. They are linear polynomials of the following form [18]:

$$
u=a_{1}+a_{2} x+a_{3} y+a_{4} x y, v=a_{5}+a_{6} x+a_{7} y+a_{8} x y
$$

where $x, y$ are the coordinates of the desired point in the coordinate grid of the blasting block.
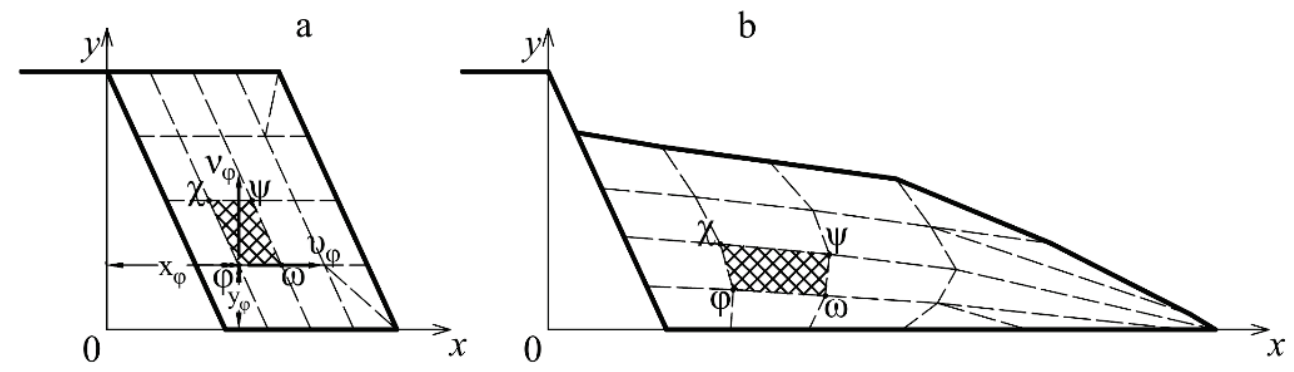

Fig. 3. The grid element in the blasting (a) and blasted (b) block of the rock mass.

As can be seen from fig. 3 some layers of the coordinate grid of the blasting and blasted blocks of the rock mass are divided into triangular elements.

The system of equations that defines the movement of points inside the coordinate grid element of the blasted block will have the following form [18]:

$$
\{\mathbf{f}\}=\left\{\begin{array}{l}
u \\
v
\end{array}\right\}=[\mathbf{N}]\{\boldsymbol{\delta}\}^{e},
$$

where $[\mathbf{N}]$ is the function of the form of the element;

$$
[\mathbf{N}]=[\mathbf{P}][\mathbf{C}]^{-1}
$$

here 


$$
[\mathbf{P}]=\left[\begin{array}{llll}
1 & x & y & x y
\end{array}\right], \quad[\mathbf{C}]=\left[\begin{array}{cccc}
1 & x_{\varphi} & y_{\varphi} & x_{\varphi} y_{\varphi} \\
1 & x_{\chi} & y_{\chi} & x_{\chi} y_{\chi} \\
1 & x_{\psi} & y_{\psi} & x_{\psi} y_{\psi} \\
1 & x_{\omega} & y_{\omega} & x_{\omega} y_{\omega}
\end{array}\right]
$$

where $x_{\varphi}, y_{\varphi}, x_{\chi}, y_{\chi}, x_{\psi}, y_{\psi}, x_{\omega}, y_{\omega}$ are the coordinates of the nodal points of the coordinate grid of the blasting block.

Knowing the final displacements of each nodal point of the element of the coordinate grid of the blasted block, the following systems of equations can be written $[18,19]$ :

$$
\left\{\begin{array}{l}
u_{\varphi} \\
u_{\chi} \\
u_{\psi} \\
u_{\omega}
\end{array}\right\}=\left[\begin{array}{llll}
a_{1} & a_{2} x_{\varphi} & a_{3} y_{\varphi} & a_{4} x_{\varphi} y_{\varphi} \\
a_{1} & a_{2} x_{\chi} & a_{3} y_{\chi} & a_{4} x_{\chi} y_{\chi} \\
a_{1} & a_{2} x_{\psi} & a_{3} y_{\psi} & a_{4} x_{\psi} y_{\psi} \\
a_{1} & a_{2} x_{\omega} & a_{3} y_{\omega} & a_{4} x_{\omega} y_{\omega}
\end{array}\right],\left\{\begin{array}{l}
v_{\varphi} \\
v_{\chi} \\
v_{\psi} \\
v_{\omega}
\end{array}\right\}=\left[\begin{array}{cccc}
a_{5} & a_{6} x_{\varphi} & a_{7} y_{\varphi} & a_{8} x_{\varphi} y_{\varphi} \\
a_{5} & a_{6} x_{\chi} & a_{7} y_{\chi} & a_{8} x_{\chi} y_{\chi} \\
a_{5} & a_{6} x_{\psi} & a_{7} y_{\psi} & a_{8} x_{\psi} y_{\psi} \\
a_{5} & a_{6} x_{\omega} & a_{7} y_{\omega} & a_{8} x_{\omega} y_{\omega}
\end{array}\right] .
$$

From this system of equations, it is easy to determine the constants $a_{1}, a_{2} \ldots a_{8}$. For this, we present the resulting system of equations in the form [19]:

$$
\left\{\begin{array}{l}
a_{1} \\
a_{2} \\
a_{3} \\
a_{4}
\end{array}\right\}=\left[\begin{array}{llll}
1 & x_{\varphi} & y_{\varphi} & x_{\varphi} y_{\varphi} \\
1 & x_{\chi} & y_{\chi} & x_{\chi} y_{\chi} \\
1 & x_{\psi} & y_{\psi} & x_{\psi} y_{\psi} \\
1 & x_{\omega} & y_{\omega} & x_{\omega} y_{\omega}
\end{array}\right]^{-1} \cdot\left\{\begin{array}{l}
u_{\varphi} \\
u_{\chi} \\
u_{\psi} \\
u_{\omega}
\end{array}\right\},\left\{\begin{array}{l}
a_{5} \\
a_{6} \\
a_{7} \\
a_{8}
\end{array}\right\}=\left[\begin{array}{cccc}
1 & x_{\varphi} & y_{\varphi} & x_{\varphi} y_{\varphi} \\
1 & x_{\chi} & y_{\chi} & x_{\chi} y_{\chi} \\
1 & x_{\psi} & y_{\psi} & x_{\psi} y_{\psi} \\
1 & x_{\omega} & y_{\omega} & x_{\omega} y_{\omega}
\end{array}\right]^{-1} \cdot\left\{\begin{array}{l}
v_{\varphi} \\
v_{\chi} \\
v_{\psi} \\
v_{\omega}
\end{array}\right\}
$$

Thus, multiplying the inverse matrix $[\mathbf{C}]$ and the displacement vectors $\{\mathbf{u}\}^{e},\{\mathbf{v}\}^{e}$ we get a column vector with the values of the desired constants $a_{1}, a_{2} \ldots a_{8}$. Substituting them into equations (12), we determine the displacement of any internal point of the coordinate grid element of the blasted block. All the above actions are true for a triangular element. To do this, it suffices to lower the dimension of the matrices and vectors by removing the components with index $\omega$ and the multiplication $x y$. The values of the calculated coordinates, displacements, and constants of the systems of equations of the element of the coordinate grid of the blasting and blasted rock mass are presented in Table. 3.

Table. 3. Coordinates, their displacements and constants of the systems of equations of the coordinate grid element of the blasting and blasted rock mass block.

\begin{tabular}{|c|c|c|c|c|c|c|c|}
\hline$x_{\varphi}, \mathrm{m}$ & $y_{\varphi}, \mathrm{m}$ & $x_{\chi}, \mathrm{m}$ & $y_{\chi}, \mathrm{m}$ & $x_{\psi}, \mathrm{m}$ & $y_{\psi}, \mathrm{m}$ & $x_{\omega}, \mathrm{m}$ & $y_{\omega}, \mathrm{m}$ \\
\hline 7.67 & 3.75 & 5.95 & 7.5 & 8.45 & 7.5 & 10.17 & 3.75 \\
\hline$u_{\varphi}, \mathrm{m}$ & $v_{\varphi}, \mathrm{m}$ & $u_{\chi}, \mathrm{m}$ & $v_{\chi}, \mathrm{m}$ & $u_{\psi}, \mathrm{m}$ & $v_{\psi}, \mathrm{m}$ & $u_{\omega}, \mathrm{m}$ & $v_{\omega}, \mathrm{m}$ \\
\hline 10.46 & 2.98 & 9.93 & 5.73 & 16.4 & 5.12 & 16.21 & 2.72 \\
\hline$a_{1}$ & $a_{2}$ & $a_{3}$ & $a_{4}$ & $a_{5}$ & $a_{6}$ & $a_{7}$ & $a_{8}$ \\
\hline-8.88 & 2.01 & 0.43 & 0.08 & 0.38 & 0.036 & 0.90 & -0.038 \\
\hline
\end{tabular}

Using the proposed methodology for the analytical determination of the internal points of coordinate grid of the block, a computer program was created in the Microsoft Visual Studio 2019 [20]. It allows for convenient and flexible calculation of the coordinates of internal points and to build a profile of the collapse of blasted rocks. According to the 
developed program, the results of mass explosions were simulated for the given parameters of drilling-blasting works on a 15-meter ledge. Examples of calculations and automated construction of a rock camber profile are shown in Figures 1, 2, 4. They confirm the efficiency of the developed analytical method for determining the coordinates of the internal points of the coordinate grid of the blasted block and automated prediction of the placement of various ledge elements in the blasted rock mass under various blasting conditions.

Illustrations of the location of ore bodies in a rock mass (Fig. 4a) and collapse (Fig. 4b, $4 \mathrm{c}, 4 \mathrm{~d}$ ), calculated by the proposed method using the developed computer program, are presented in Figure 4.
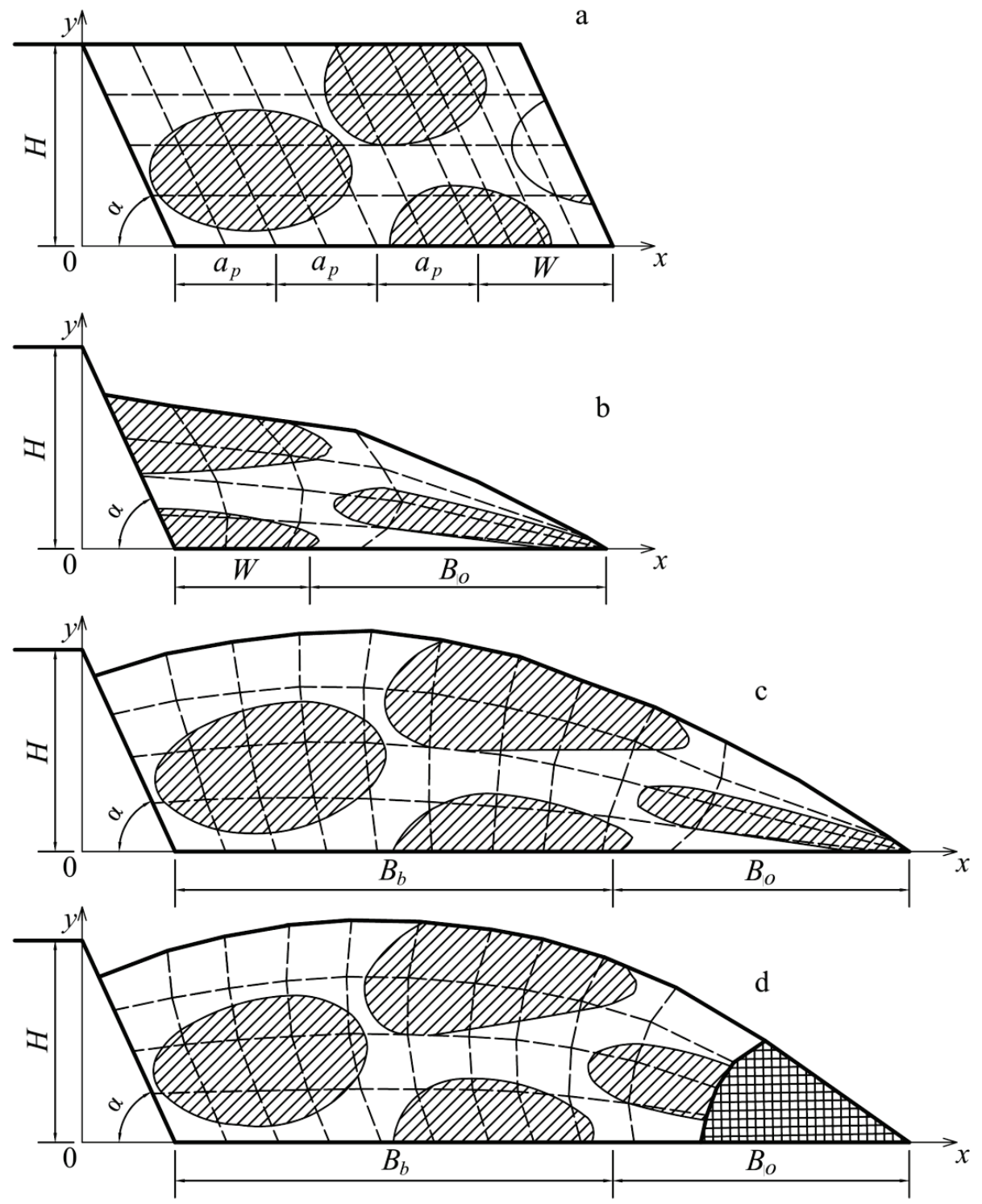

Fig. 4. Layout of ore bodies in the blasting (a) and blasted blocks in case of single-row blasting (b), four-row short blast on a free surface (c) and with a retaining wall (d). 


\section{Conclusion}

For the first time in mining, original analytical methods have been developed for determining the nodal and internal points of the coordinate grid of the blasted rock mass. They are based on some basic techniques of analytic geometry, matrix theory, and linear algebra.

The use of these methods in the educational process when designing the results of the explosion, the technology of excavation and loading operations allows you to explicitly demonstrate the advantages and disadvantages of the applied mining technologies.

A computer program has been developed for the automated determination of the internal points of the coordinate grid of the blasted block of rock mass. The obtained results serve as a reliable tool for the operational determination of the location of various ledge elements in the collapse: ore inclusions of various configurations, various crushing zones, etc.

The developed analytical method and its computer support make it possible to quickly and fairly accurately predict the placement of various ledge elements in the collapse and recommend drilling and blasting and excavation and loading technologies to reduce ore loss and dilution, increase the productivity of mining equipment.

\section{References}

1. Pokrovsky, G. I., Fedorov, I. S. (1957). The action of shock and explosion in deformable media. Moscow: Promstroyizdat

2. Rakishev. B. R. (2016). Automated design and production of mass explosions in quarries. Almaty: Gylym

3. Rakishev, B. R., Shampikova, A. Kh., Kazangapov, A. E. (2018). Mining and geological characteristics of blown up structural blocks. Vzryvnoe delo, 120/77, 82-93

4. Viktorov, S. D., Frantov, A. E., Zakalinsky, V. M. (2019). Theory - technology blasting technology using conversion explosives in mining processes. Moskow: IPKON RAN

5. Viktorov. S. D. (2015). Explosive destruction of rock masses - the basis of progress in mining. Gornyy informatsionno-analiticheskiy byulleten, S1, 63-75

6. Kazakov, N. N., Shlyapin, A. V. (2018). Determination of tensor stress-strain state of rocks during explosion of a borehole charge. Gornyy informatsionno-analiticheskiy byulleten, S1, 112-126

7. Paramonov, G. P., Kovalevsky, V. N., Mysin, A. V. (2019). Numerical simulation of the destruction of a rock block by an explosion taking into account laboratory experiments. Vzryvnoe delo. 122/79, 19-33

8. Kazakov N. N. (2018) Destruction and crushing of rocks in quarries. Vzryvnoe delo, 119/76, 5-19

9. An, H. M. \& Liu, Hongyuan \& Han, Haoyu \& Zheng, Xin \& Wang, X. G. Hybrid finite-discrete element modelling of dynamic fracture and resultant fragment casting and muck-piling by rock blast. Computers and Geotechnics, 81, 322-345, 10.1016/j.compgeo.2016.09.007 (2017).

10. Bakhshandeh Amnieh, Hassan, Moein, Bahadori. Numerical Analysis of the Primer Location Effect on Ground Vibration Caused by Blasting. International Journal of Mining and Geo-Engineering, 51.1, 53-62 (2017)

11. Damjanac Branko, Christine Detournay, Peter A. Cundall. Application of particle and lattice codes to simulation of hydraulic fracturing. Computational Particle Mechanics, 3.2, 249-261 (2016)

12. Furtney, J. K., Andrieux, P., Hall, A. K. Applications for Numerical Modeling of Blast Induced Rock Fracture. American Rock Mechanics Association. 621, 7 (2016). 
13. Mao, Z. et al. A conservative and consistent Lagrangian gradient smoothing method for earthquake-induced landslide simulation. Engineering Geology, 260, 105226 (2019)

14. Galyanov, A. V., Rozhdestvensky, V. N., Blinov, A. N. (1999) Transformation of the structure of massifs during blasting in quarries. Ekaterinburg: ITD UrORAN

15. Laurent, P. J. (1975). Approximation and optimization. Moscow: Mir

16. Filippov, A. S. (2016). Numerical methods in the mechanics of a deformable solid. Moscow: MFTI

17. Moaveni, S. Finite element analysis theory and application with ANSYS, 3rd Edition. Pearson Education India. (2011)

18. Zenkevich, O. (1975). Method of finite elements in technology. Moscow: Mir

19. Gantmakher, F. R. (1966). Matrix theory. Moscow: Nauka

20. Lars Powers, Mike Snell, Microsoft Visual Studio 2015 Unleashed, 3rd Edition (Indianapolis, Imprint Sams, 2015) 